\title{
A Method to Optimize Geometric Errors of Machine Tool based on SNR Quality Loss Function and Correlation Analysis
}

\author{
Ligang Cai ${ }^{1}$, Jiaying $\mathrm{Li}^{1}$, Qiang Cheng ${ }^{1,2}$, Bingwei Sun ${ }^{1}$ and Yan Wang ${ }^{1}$ \\ ${ }^{1}$ Beijing Key Laboratory of Advanced Manufacturing Technology, Beijing University of Technology, Beijing 100124, China \\ ${ }^{2}$ Key Laboratory of High Performance Complex Manufacturing, Central South University, Changsha, Hunan, 4310083, China
}

\begin{abstract}
Instead improving the accuracy of machine tool by increasing the precision of key components level blindly in the production process, the method of combination of SNR quality loss function and machine tool geometric error correlation analysis to optimize five-axis machine tool geometric errors will be adopted. Firstly, the homogeneous transformation matrix method will be used to build five-axis machine tool geometric error modeling. Secondly, the SNR quality loss function will be used for cost modeling. And then, machine tool accuracy optimal objective function will be established based on the correlation analysis. Finally, ISIGHT combined with MATLAB will be applied to optimize each error. The results show that this method is reasonable and appropriate to relax the range of tolerance values, so as to reduce the manufacturing cost of machine tools.
\end{abstract}

\section{Introduction}

With the development of advanced manufacturing technology, the requirement of machine tool is increasing, which is not only reflected in the machining accuracy of the machine tool, but also reducing costs that can meet the demand of the market. Although the machining accuracy is an important index to measure the performance of the machine, reducing the production cost of CNC machine tools also has important significance in the premise of ensuring the processing precision.

In order to facilitate the research of the relationship between machining accuracy and production cost, the error modeling is the most important task. Domestic and foreign scholars has carried out many researches in the field of machine tool error modeling and proposed many modeling method, such as kinematics model method [1], mechanism method [2], neural network method [3-4], homogeneous transformation matrix method [5], screw theory method [6], etc. These methods can accurately establish the accuracy model of the machine tool, and it is the basis of the research of all aspects of the machine tool. In this paper, the method of homogeneous transformation matrix is used to model the error model of five axis machine tool.

After the machine tool error model is established, the research between the total cost and precision machine tool will be carried out. At first, the tolerance optimization model based on the SNR quality loss function will be established, serving as cost basis to achieve optimal allocation of each parts tolerance. At present, some domestic scholars have some improvement on the quality loss function. Feng et al. [7] proposed an improved multivariate quality loss function, which can be used for all the quality characteristics, and fully considered the correlation between the corresponding variables. Ai et al. [8] combined multivariate quality loss function and genetic algorithm to optimize the assembly quality. Duan et al. [9] improved the multivariate quality loss function, the incremental model of multivariate quality loss function is formed, and the feasibility of the model is proved by an example. Chang et al. [10] consider the trade-off problem between quality and cost for the case when the input quality characteristic is normally distributed. According to the research of Chen et al. [11], the management can adjust the investment on prevention and appraisal costs on quality improvement that enhances process capability, reduces product defect rate and, as a result, generates remarkable financial return. Ram Ganeshan et al. [12] established a model which determines the optimal levels of inventory, and the production lot-size that minimizes the sum of inventory and quality-related costs. Noel Artiles-León [13] described a methodology for optimizing several quality characteristics simultaneously. It was assumed that some type of experimentation had been carried out to determine a relationship between each quality characteristic and the experimental factors. Ramesh Kumar et al. [14] applied quality loss theory to allocate tolerance economically and precisely. Balamurugan, C. et al [15] finished the optimal allocation of geometric and process tolerances based on the present worth of quality loss. Pradeep Kumar Gupta et al [16] enhanced machine accuracy by economic analysis.

Optimization model based on the correlation analysis of the geometric error of machine tool is regarded as 
another geometric error basis for the optimal allocation of each parts tolerance. There are also some researches in this respect at present, the commonly used correlation analysis method are Two step cluster [17], K - Means cluster [18], and Hierarchical cluster [19]. Hierarchical cluster analysis is a multivariate statistical analysis method, which is widely used to establish a classification. This method in the SPSS will be used to cluster and analyze the 37 geometric errors of five-axis machine tool.

In this paper, based on the combination of the SNR quality loss function and the geometric error correlation analysis, the tolerance distribution model of the machine tool can be obtained, and the tolerance of the machine tool will be optimized. This method can ensure the machining accuracy of the machine, and appropriately increase geometric errors, so that it can reduce the cost of machine tools, which has a positive effect on the development of the machine tool market.

\section{Error modeling of five-axis machine tool based on homogeneous transformation matrix}

In this paper, the XKH800 five-axis linkage blade machining center is used to develop the geometric error model. Three-dimensional model of this XHK800 fiveaxis machining center is shown in Figure 1. There are 37 geometric errors including positioning errors, straightness errors, angular errors, etc., which are shown in Table 1. The topological structure of this machining center is shown in Figure 2. The homogeneous transformation matrices of the machine tool between the moving parts are shown in Table 2.

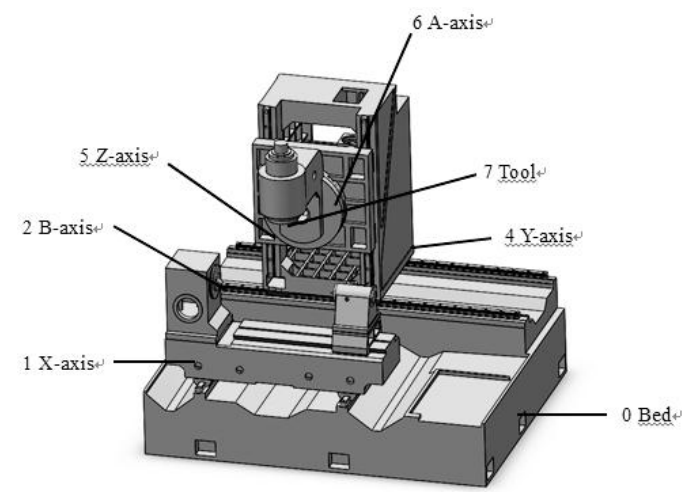

Figure 1. The three-dimensional model of the XHK800 fiveaxis machining center.

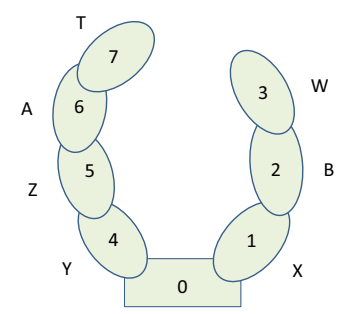

Figure 2. The topological structure of the XHK800 fiveaxis machining center.
Suppose that the tool forming point coordinate in the tool coordinate system is:

$$
P_{t}=\left(\begin{array}{llll}
p_{t x} & p_{t y} & p_{t z} & 1
\end{array}\right)^{T}
$$

The work-piece forming point coordinate in the workpiece coordinate system is:

$$
P_{w}=\left(\begin{array}{llll}
p_{w x} & p_{w y} & p_{w z} & 1
\end{array}\right)^{T}
$$

When the machine tool moves in ideal case, the machine tool is without error, that means the tool forming point and work-piece forming point will overlap together, which can be described as:

$$
T_{07} P_{t}=T_{03} P_{\text {wideal }}
$$

The ideal tool forming point in the work-piece coordinate system can be obtained according to Eq. (3):

$$
P_{\text {wideal }}=\left(T_{01}^{P} T_{01}^{S} T_{12}^{P} T_{12}^{S} T_{23}^{P} T_{23}^{S}\right)^{-1} T_{04}^{P} T_{04}^{S} T_{45}^{P} T_{45}^{S} T_{56}^{P} T_{56}^{S} T_{67}^{P} T_{67}^{S} P_{t}
$$

In Eq. (4), $\mathrm{P}$ and $\mathrm{S}$ mean static and dynamic respectively, so $T_{J-1, J}^{P}$ refers to the ideal static homogenous transformation matrix of the adjacent body and $T_{J-1, J}^{S}$ refers to the ideal dynamic homogenous transformation matrix as shown in Table 3 . In the actual machining process, the position of actual tool forming point will inevitably deviate from the ideal. Therefore, the actual tool forming point in the work-piece coordinate system is:

$$
P_{\text {wactrual }}=\left({ }^{E} T_{03}\right){ }^{-1 E} T_{07} P_{t}
$$

And thereupon, geometric errors of five-axis machine tool caused by the gap between actual and ideal forming point can be described as:

$$
E={ }^{E} T_{03} P_{\text {wideal }}-{ }^{E} T_{07} P_{t}
$$

The values of the expressions in the Eq. (4)-Eq. (6) can be checked from Table 2. E represents geometric errors of this machining center including $E_{x}, E_{y}$, and $E_{z}$, which is:

$$
E=\left[\begin{array}{llll}
E_{x} & E_{y} & E_{z} & 1
\end{array}\right]^{T}
$$

\section{Tolerance optimal allocation modeling based on the total cost of the SNR quality loss function}

This model consists of two parts: manufacturing cost function and SNR quality loss function. Manufacturing cost function control the precondition which is meeting the requirements of product performance and the lowest manufacturing cost, and optimize the parts tolerance. The basic purpose of quality loss function is to evaluate the loss caused by low quality in a quantitative way [7]. 


\subsection{Manufacturing cost}

In this article, the tolerance and accuracy of the 37 machine tool geometric errors are supposed to be $T_{i}$ and $A_{i}$ separately. Suppose that the half tolerance bandwidth of machine tool geometric accuracy is $t_{i}\left(t_{i}=T_{i} / 2 ; \mathrm{i}=1\right.$, 2...37). As the implementation cost of the machine tool geometric accuracy is different, the cost weight coefficient $h_{i}$ and the cost characteristic index $r_{i}$ are introduced. The cost of the machine tool can be expressed as:

$$
C_{\Sigma}\left(t_{i}\right)=\sum_{i=1}^{37}\left(\mathrm{~h}_{i} \mathrm{t}_{i}\right)^{-r_{i}}
$$

Table 1. Description and representation of the five-axis machine tool geometric errors.

\begin{tabular}{|c|c|c|c|}
\hline $\begin{array}{c}\text { Identification } \\
\text { mark }\end{array}$ & Geometrical significance & $\begin{array}{c}\text { Identification } \\
\text { mark }\end{array}$ & Geometrical significance \\
\hline$\Delta x_{x}$ & positioning error & $\Delta x_{A}$ & $\mathrm{X}$ direction run-out error \\
\hline$\Delta y_{x}$ & $\begin{array}{l}\begin{array}{l}\text { Y direction of straightness } \\
\text { error }\end{array} \\
\text { ? }\end{array}$ & $\Delta y_{A}$ & Y direction run-out error \\
\hline$\Delta z_{x}$ & $\begin{array}{l}\mathrm{Z} \text { direction of straightness } \\
\text { error }\end{array}$ & $\Delta z_{A}$ & $\mathrm{Z}$ direction run-out error \\
\hline$\Delta \alpha_{x}$ & Roll error & $\Delta \alpha_{A}$ & Turning error \\
\hline$\Delta \beta_{x}$ & Pitch error & $\Delta \beta_{A}$ & $\begin{array}{c}\text { Around the Y-axis turning } \\
\text { error }\end{array}$ \\
\hline$\Delta \gamma_{x}$ & Yaw error & $\Delta \gamma_{A}$ & $\begin{array}{c}\text { Around the Z-axis turning } \\
\text { error }\end{array}$ \\
\hline$\Delta x_{y}$ & $\begin{array}{l}\text { X direction of straightness } \\
\text { error }\end{array}$ & $\Delta x_{B}$ & $\mathrm{X}$ direction run-out error \\
\hline$\Delta y_{y}$ & positioning error & $\Delta y_{B}$ & Y direction run-out error \\
\hline$\Delta z_{y}$ & $\begin{array}{l}\mathrm{Z} \text { direction of straightness } \\
\text { error }\end{array}$ & $\Delta z_{B}$ & $\mathrm{Z}$ direction run-out error \\
\hline$\Delta \alpha_{y}$ & Pitch error & $\Delta \alpha_{B}$ & $\begin{array}{l}\text { Around the } \mathrm{X} \text {-axis turning } \\
\text { error }\end{array}$ \\
\hline$\Delta \beta_{y}$ & Roll error & $\Delta \beta_{B}$ & Turning error \\
\hline$\Delta \gamma_{y}$ & Yaw error & $\Delta \gamma_{B}$ & $\begin{array}{c}\text { Around the Z-axis turning } \\
\text { error }\end{array}$ \\
\hline$\Delta x_{z}$ & $\begin{array}{l}\text { X direction of straightness } \\
\text { error }\end{array}$ & $\Delta \gamma_{x y}$ & $\begin{array}{c}\mathrm{X}, \mathrm{Y} \text {-axis perpendicularity } \\
\text { error }\end{array}$ \\
\hline$\Delta y_{z}$ & $\begin{array}{l}\text { Y direction of straightness } \\
\text { error }\end{array}$ & $\Delta \beta_{x z}$ & $\begin{array}{c}\mathrm{X}, \mathrm{Z} \text {-axis perpendicularity } \\
\text { error }\end{array}$ \\
\hline$\Delta z_{z}$ & positioning error & $\Delta \alpha_{y z}$ & $\begin{array}{l}\text { Y,Z-axis perpendicularity } \\
\text { error }\end{array}$ \\
\hline$\Delta \alpha_{z}$ & Pitch error & $\Delta \gamma_{x B}$ & $\begin{array}{c}\text { B-axis parallelism error in } \\
\text { YZ plane }\end{array}$ \\
\hline$\Delta \beta_{z}$ & Yaw error & $\Delta \alpha_{z B}$ & $\begin{array}{c}\text { B-axis parallelism error in } \\
\text { XY plane }\end{array}$ \\
\hline \multirow[t]{2}{*}{$\Delta \gamma_{z}$} & Roll error & $\Delta \gamma_{y A}$ & $\begin{array}{c}\text { A-axis parallelism error in } \\
\mathrm{XZ} \text { plane }\end{array}$ \\
\hline & & $\Delta \beta_{z A}$ & $\begin{array}{c}\text { A-axis parallelism error in } \\
\text { XY plane }\end{array}$ \\
\hline
\end{tabular}

Table 2. Ideal and error homogeneous transformation matrixes of the five-axis machine tool.

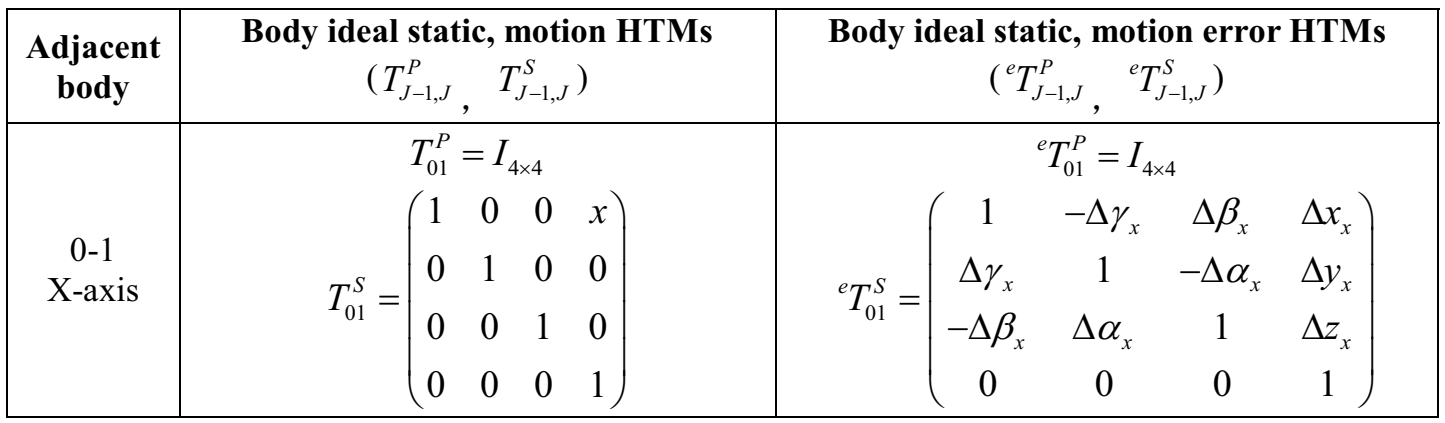




\begin{tabular}{|c|c|c|c|c|c|c|c|c|c|}
\hline $\begin{array}{c}1-2 \\
\text { B-axis }\end{array}$ & $T_{12}^{S}=\left(\begin{array}{l}\mathrm{co} \\
-\mathrm{s}\end{array}\right.$ & $\begin{array}{ll}{ }_{12}^{P}= & I_{4 \times 4} \\
3 & 0 \\
& 1 \\
B & 0 \\
& 0\end{array}$ & $\begin{array}{c}\sin B \\
0 \\
\cos B \\
0\end{array}$ & $\left.\begin{array}{l}0 \\
0 \\
0 \\
1\end{array}\right)$ & ${ }^{e} T_{12}^{P}=$ & $\begin{array}{c}\left(\begin{array}{c}1 \\
\Delta \gamma_{x B} \\
0 \\
0\end{array}\right. \\
\left(\begin{array}{c}1 \\
\Delta \gamma_{B} \\
-\Delta \beta_{B} \\
0\end{array}\right.\end{array}$ & $\begin{array}{c}-\Delta \gamma_{x B} \\
1 \\
\Delta \alpha_{z B} \\
0 \\
-\Delta \gamma_{B} \\
1 \\
\Delta \alpha_{B} \\
0\end{array}$ & $\begin{array}{c}0 \\
-\Delta \alpha_{z B} \\
1 \\
0 \\
\Delta \beta_{B} \\
-\Delta \alpha_{B} \\
1 \\
0\end{array}$ & $\left.\begin{array}{c}0 \\
0 \\
0 \\
1\end{array}\right)$ \\
\hline $\begin{array}{c}2-3 \\
\text { Work } \\
\text { piece }\end{array}$ & $T_{23}^{P}=$ & $\begin{array}{rr}0 & 0 \\
1 & 0 \\
0 & 1 \\
0 & 0 \\
S & =I_{4 \times 4} \\
23 & =\end{array}$ & $\begin{array}{c}x_{w d} \\
y_{w d} \\
z_{w d} \\
1 \\
4 \\
\end{array}$ & & ${ }^{e} T_{23}^{P}=$ & $\begin{array}{c}1 \\
\Delta \gamma_{w d} \\
-\Delta \beta_{w d} \\
0\end{array}$ & $\begin{array}{c}-\Delta \gamma_{w d} \\
1 \\
\Delta \alpha_{w d} \\
0 \\
{ }^{e} T_{23}^{S}=I_{4 \times 4}\end{array}$ & $\begin{array}{c}\Delta \beta_{w d} \\
-\Delta \alpha_{w d} \\
1 \\
0 \\
4\end{array}$ & $\begin{array}{c}\Delta x_{w d} \\
\Delta y_{w d} \\
\Delta z_{w d} \\
1\end{array}$ \\
\hline $\begin{array}{c}0-4 \\
\text { Y-axis }\end{array}$ & $T_{04}^{S}=$ & $\begin{array}{lll}P_{04} & = & I_{4 \times 4} \\
1 & 0 & 0 \\
1 & 0 & 0 \\
0 & 1 & 0 \\
0 & 0 & 1 \\
0 & 0 & 0\end{array}$ & $\left.\begin{array}{ll}4 & \\
0 & 0 \\
0 & y \\
1 & 0 \\
0 & 1\end{array}\right)$ & & ${ }^{e} T_{04}^{S}=$ & $\begin{array}{l}\Gamma_{04}^{P}=\left(\begin{array}{c}1 \\
\Delta \gamma \\
0 \\
0\end{array}\right. \\
=\left(\begin{array}{c}1 \\
\Delta \gamma_{y} \\
-\Delta \beta_{y} \\
0\end{array}\right.\end{array}$ & \begin{tabular}{rr}
1 & $-\Delta \gamma$ \\
$\gamma_{x y}$ & 1 \\
0 & 0 \\
0 & 0 \\
$-\Delta \gamma_{y}$ \\
1 \\
\multicolumn{1}{c}{$\begin{array}{l}\alpha_{y} \\
0\end{array}$} \\
0
\end{tabular} & $\begin{array}{rrr}x_{x y} & 0 & 0 \\
& 0 & 0 \\
& 0 \\
& 0 \\
& 0 & 1 \\
\Delta \beta_{y} \\
-\Delta \alpha_{y} \\
1 \\
0\end{array}$ & 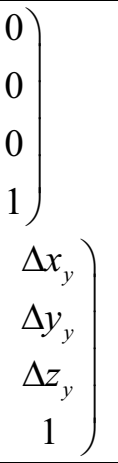 \\
\hline $\begin{array}{c}4-5 \\
\text { Z-axis }\end{array}$ & $T_{45}^{S}=$ & \begin{tabular}{lll}
$P$ & $=$ & $I_{4 \times 4}$ \\
1 & \multicolumn{1}{l}{} & \\
1 & 0 & 0 \\
0 & 1 & 0 \\
0 & 0 & 1 \\
0 & 0 & 0 \\
0 & 0
\end{tabular} & $\left.\begin{array}{ll}4 & \\
0 & 0 \\
0 & 0 \\
1 & z \\
0 & 1\end{array}\right)$ & & ${ }^{e} T_{45}^{P}=$ & $\begin{array}{r}=\left(\begin{array}{c}1 \\
0 \\
-\Delta \beta_{x z} \\
0\end{array}\right. \\
=\left(\begin{array}{c}1 \\
\Delta \gamma_{z} \\
-\Delta \beta_{z} \\
0\end{array}\right.\end{array}$ & $\begin{array}{c}0 \\
1 \\
\Delta \alpha_{y z} \\
0 \\
-\Delta \gamma_{z} \\
1 \\
\Delta \alpha_{z} \\
0\end{array}$ & $\begin{array}{c}\Delta \beta_{x z} \\
-\Delta \alpha_{y z} \\
1 \\
0 \\
\Delta \beta_{z} \\
-\Delta \alpha_{z} \\
1 \\
0\end{array}$ & $\left.\begin{array}{r}0 \\
z \\
0 \\
0 \\
1\end{array}\right)$ \\
\hline $\begin{array}{c}5-6 \\
\text { A-axis }\end{array}$ & $T_{56}^{S}=\left(\begin{array}{l}1 \\
0 \\
0 \\
0\end{array}\right.$ & $\begin{array}{l}{ }_{56}^{P}=I_{4 \times 4} \\
0 \\
\text { os } A- \\
\text { in } A \quad \text { c } \\
0\end{array}$ & $\begin{array}{c}0 \\
-\sin A \\
\cos A \\
0\end{array}$ & $\begin{array}{l}0 \\
0 \\
0 \\
1\end{array}$ & ${ }^{e} T_{56}^{S}=$ & $\begin{array}{l}=\left(\begin{array}{c}1 \\
\Delta \gamma_{y A} \\
-\Delta \beta_{z} \\
0\end{array}\right. \\
=\left(\begin{array}{c}1 \\
\Delta \gamma_{A} \\
-\Delta \beta_{A} \\
0\end{array}\right.\end{array}$ & $\begin{array}{c}-\Delta \gamma_{y A} \\
1 \\
0 \\
0 \\
-\Delta \gamma_{A} \\
1 \\
\Delta \alpha_{A} \\
0\end{array}$ & $\begin{array}{c}\Delta \beta_{z A} \\
0 \\
1 \\
0 \\
\Delta \beta_{A} \\
-\Delta \alpha_{A} \\
1 \\
0\end{array}$ & $\left.\begin{array}{c}0 \\
0 \\
0 \\
1\end{array}\right)$ \\
\hline $\begin{array}{c}6-7 \\
\text { Tool }\end{array}$ & $T_{67}^{P}=$ & $\begin{array}{ccc}1 & 0 & 0 \\
0 & 1 & 0 \\
0 & 0 & 1 \\
0 & 0 & 0 \\
T_{67}^{S} & =I_{4 \times 4} \\
6\end{array}$ & $\left.\begin{array}{c}x_{t d} \\
y_{t d} \\
z_{t d} \\
1\end{array}\right)$ & & ${ }^{e} T_{67}^{P}=$ & $\left(\begin{array}{c}1 \\
\Delta \gamma_{t d} \\
-\Delta \beta_{t d} \\
0\end{array}\right.$ & $\begin{array}{c}-\Delta \gamma_{t d} \\
1 \\
\Delta \alpha_{t d} \\
0 \\
T_{67}^{P}=I_{4 \times}\end{array}$ & $\begin{array}{c}\Delta \beta_{t d} \\
-\Delta \alpha_{t d} \\
1 \\
0 \\
\end{array}$ & $\left.\begin{array}{c}\Delta x_{t d} \\
\Delta y_{t d} \\
\Delta z_{t d} \\
1\end{array}\right)$ \\
\hline
\end{tabular}


In order to determine the cost weight coefficient, the 37 geometric accuracies of machine tool are classified according to the categories, and it is considered that the cost weight coefficient of the same type of machine tool's geometric accuracy is the same. Linear displacement positioning accuracy is regarded as a benchmark, of which the cost weight coefficient is 1 . And introducing 3 proportionality coefficients $h_{p}, h_{a}$, and $h_{d}$, which severally means the ratio of the cost weight coefficient of positional accuracy, angular displacement positioning accuracy and non-positioning accuracy to the cost weight coefficient of linear displacement positioning accuracy, and they are shown in Table 3. According to the specific structure of the machine tool chosen by this paper and the reference [20] [21], This paper set up $h_{p}=3, h_{a}=4$, $h_{d}=5, r_{i}=2$.

Table 3. The classification and cost weight coefficient of machine tool geometric accuracy.

\begin{tabular}{|c|c|c|c|}
\hline & Category & The symbol of geometric accuracy & $\begin{array}{l}\text { Cost weight } \\
\text { coefficient }\end{array}$ \\
\hline & itional accuracy & $\begin{array}{lllllll}A_{31} & A_{32} & A_{33} & A_{34} & A_{35} & A_{36} & A_{37}\end{array}$ & $h_{p}$ \\
\hline & $\begin{array}{l}\text { Linear displacement } \\
\text { positioning accuracy }\end{array}$ & $A_{1} A_{8} A_{15}$ & 1 \\
\hline & Angle position precision & $A_{22} A_{29}$ & $h_{a}$ \\
\hline $\begin{array}{l}\text { Kinematic } \\
\text { accuracy }\end{array}$ & $\begin{array}{l}\text { Linear displacement non- } \\
\text { positioning accuracy }\end{array}$ & 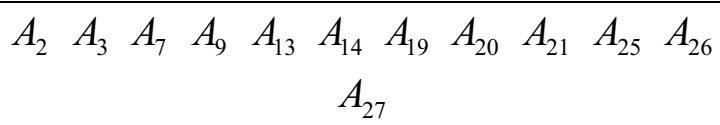 & $h_{d}$ \\
\hline & $\begin{array}{l}\text { Angle non-position } \\
\text { precision }\end{array}$ & 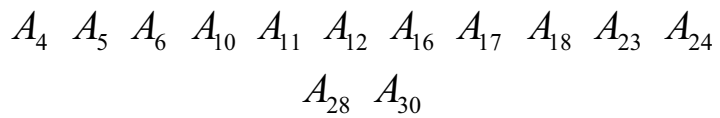 & $h_{a} h_{d}$ \\
\hline
\end{tabular}

\subsection{Cost of quality loss based on signal-noise ratio}

The smaller-the-better characteristic refers to the closer to zero the better quality characteristics.

In the actual calculation, the SNR of the smaller-thebetter characteristic is:

$$
\eta_{S}=10 \log \frac{1}{\sigma^{2}+\mu^{2}}
$$

Its estimated value is:

$$
\eta_{S}=10 \log \frac{1}{\sigma^{2}+\mu^{2}}=-10 \log \left(\frac{1}{n} \sum_{i=1}^{n} y_{i}^{2}\right)
$$

The greater the value of $\eta$ is, the product quality will be more stable, and the loss smaller [22]. According to this conclusion, the size of the contribution of the quality indicators to the volatility will be determined, and different weights can be assigned:

$$
\lambda_{i}=\frac{\frac{1}{\eta_{i}}}{\sum_{j=1}^{n} \frac{1}{\eta_{j}}}
$$

In this paper, 37 geometric errors can be regards as the quality characteristics of the machine tool, and they are the smaller-the-better characteristic. The multivariate quality loss function of the smaller-the-better characteristic can be expressed as:

$$
L\left(y_{1}, y_{2} \ldots y_{n}\right)=\sum_{i=1}^{n} \lambda_{i} L_{S}\left(y_{i}\right)=\sum_{i=1}^{n} \lambda_{i} y_{i}^{2}
$$

Calculating SNR $\eta_{i}$ of the 37 quality indexes $t_{i}$ by Eq. (10), and replacing them into Eq. (11) and Eq. (12) in turn, the quality loss function of 37 geometric errors will be obtained:

$$
L_{\Sigma}\left(t_{i}\right)=\sum_{i=1}^{37} \lambda_{i} t_{i}^{2}
$$

\subsection{Total cost optimization model}

The sum of the cost of integrated manufacturing and quality lose reaches the minimum, which is the evidence of tolerance optimization allocation of various parts [23]. According to the manufacturing cost and quality loss cost mentioned above, the objective function of the machine total cost can be expressed as:

$$
M 1_{\min }\left[C_{\Sigma}\left(t_{i}\right)+L_{\Sigma}\left(t_{i}\right)\right]=\min \left[\sum_{i=1}^{37}\left(\mathrm{~h}_{i} \mathrm{t}_{i}\right)^{-r_{i}}+\sum_{i=1}^{37} \lambda_{i} t_{i}^{2}\right]
$$

Constraint conditions are:

$$
\begin{aligned}
& \Delta x_{\text {max }} \leq \operatorname{def}(\Delta x) \\
& \Delta y_{\text {max }} \leq \operatorname{def}(\Delta y) \\
& \Delta z_{\text {max }} \leq \operatorname{def}(\Delta z)
\end{aligned}
$$

In Eq. (15), $\operatorname{def}(\Delta x)-$ Maximum allowable error in $\mathrm{X}$ direction; $\operatorname{def}(\Delta y)$ - - Maximum allowable error in $\mathrm{Y}$ direction; $\operatorname{def}(\Delta z)-$ Maximum allowable error in $\mathrm{Z}$ direction. 


\section{Optimal distribution model based on machine tool geometric error correlation analysis}

\subsection{Machine tool geometric error correlation statistics analysis and classification}

In this article hierarchical clustering method in the SPSS (Statistical Product and Service Solutions) is applied to count the correlationship between each error term, and the error terms which ones have stronger relationship are divided into a category. According to the subsequent requirements of modeling, geometric error terms will be divided into four categories. The first kind contains $\Delta \alpha_{x}$ 、

$\Delta \beta_{x} 、 \Delta \gamma_{x} 、 \Delta \alpha_{y} 、 \Delta \beta_{y} 、 \Delta \gamma_{y} 、 \Delta \alpha_{z} 、 \Delta \beta_{z} 、 \Delta \gamma_{z} 、$ $\Delta \alpha_{A} 、 \Delta \beta_{A} 、 \Delta \alpha_{B} 、 \Delta \beta_{B} 、 \Delta \gamma_{B} 、 \Delta \gamma_{x y} 、 \Delta \beta_{x z} 、 \Delta \alpha_{y z} 、$
$\Delta \gamma_{x B} 、 \Delta \alpha_{z B} 、 \Delta \gamma_{y A} 、 \Delta \beta_{z A}$. The second kind contains $\Delta z_{y}$. The third kind contains $\Delta x_{A}, \Delta y_{A}, \Delta z_{A}, \Delta \gamma_{A}$ 、 $\Delta x_{B}, \Delta y_{B}, \Delta z_{B}$. And the forth kind contains $\Delta x_{x} 、 \Delta y_{x}$ 、 $\Delta z_{x}, \Delta x_{y}, \Delta y_{y}, \Delta x_{z}, \Delta y_{z}, \Delta z_{z}$.

\subsection{The optimal distribution model based on precision grade of machine tool key components}

There is a certain mutual influence between the geometric errors of machine tools and the geometric precision of components. According to the relationship between the components precision parameters and the geometric errors, the precision parameters of components are regarded as design variables, and the following objective function can be constructed.

$$
\begin{aligned}
& M 2_{\max }=\max \sqrt{\sum_{i=1}^{3} \Delta s_{i}{ }^{2}(x)+\sum_{j=1}^{3} \Delta s_{j}{ }^{2}(y)+\sum_{k=1}^{3} \Delta s_{k}{ }^{2}(z)+\sum_{m=1}^{3} \Delta s_{m}{ }^{2}(A)+\sum_{l=1}^{3} \Delta s_{l}{ }^{2}(B)+S^{2}(x)+S^{2}(y)+S^{2}(z)+S^{2}(A)+S^{2}(B)} \\
& =\max \sqrt{t_{1}{ }^{2}+t_{2}{ }^{2}+t_{3}{ }^{2}+t_{4}{ }^{2}+t_{7}{ }^{2}+t_{8}{ }^{2}+t_{9}{ }^{2}+t_{11}{ }^{2}+t_{13}{ }^{2}+t_{14}{ }^{2}+t_{15}{ }^{2}+t_{18}{ }^{2}+t_{19}{ }^{2}+t_{20}{ }^{2}+t_{21}{ }^{2}+t_{22}{ }^{2}+t_{25}{ }^{2}+t_{26}{ }^{2}+t_{27}{ }^{2}+t_{29}{ }^{2}}
\end{aligned}
$$

Combined with the results of the previous error terms correlation analysis and classification, the formula (16) is changed into the following form and the optimal matching model is obtained based on the correlation analysis of the machine tool geometric errors.

$$
M 2_{\max }=\max \left(\sqrt{t_{1}{ }^{2}+t_{2}{ }^{2}+t_{3}{ }^{2}+t_{7}{ }^{2}+t_{8}{ }^{2}+t_{13}{ }^{2}+t_{14}{ }^{2}+t_{15}{ }^{2}}+\sqrt{t_{4}{ }^{2}+t_{11}{ }^{2}+t_{18}{ }^{2}+t_{22}{ }^{2}+t_{29}{ }^{2}}+\sqrt{t_{9}{ }^{2}}+\sqrt{t_{19}{ }^{2}+t_{20}{ }^{2}+t_{21}{ }^{2}+t_{25}{ }^{2}+t_{26}{ }^{2}+t_{27}{ }^{2}}\right)
$$

The constraint conditions are as follows:

$$
\begin{aligned}
& \Delta x_{\max } \leq \operatorname{def}(\Delta x) \\
& \Delta y_{\max } \leq \operatorname{def}(\Delta y) \\
& \Delta z_{\max } \leq \operatorname{def}(\Delta z) \\
& l b\left(\Delta s_{i}(u)\right) \leq \Delta s_{i}(u) \leq u b\left(\Delta s_{i}(u)\right) \\
& (i=1,2,3 ; u=x, y, z) \\
& l b(S(u)) \leq S(u) \leq u b(S(u)) \\
& (u=x, y, z)
\end{aligned}
$$

In the constraint conditions, the last two inequalities limit the upper and lower bounds of the component accuracy parameters. Meanwhile, the implied condition is that the difference between the precision parameters of the same component is not too large, and the optimized variable value should be greater than the standard value.

\subsection{Tolerance optimal distribution model of machine tool}

From the foregoing, the optimization problem of this paper can be understood as the goal of minimizing the total cost and the maximization of the Euclidean norm of error terms in the constraint condition of ensuring the machining accuracy of the machine tool. The optimization model is as follows:

$$
\begin{aligned}
& M 1_{\min }\left[C_{\Sigma}\left(t_{i}\right)+L_{\Sigma}\left(t_{i}\right)\right]=\min \left[\sum_{i=1}^{37}\left(\mathrm{~h}_{i} \mathrm{t}_{i}\right)^{-r_{i}}+\sum_{i=1}^{37} \lambda_{i} t_{i}{ }^{2}\right] \\
& M 2_{\max }=\max \left(\sqrt{t_{1}{ }^{2}+t_{2}{ }^{2}+t_{3}{ }^{2}+t_{7}{ }^{2}+t_{8}{ }^{2}+t_{13}{ }^{2}+t_{14}{ }^{2}+t_{15}{ }^{2}}+\sqrt{t_{4}{ }^{2}+t_{11}{ }^{2}+t_{18}{ }^{2}+t_{22}{ }^{2}+t_{29}{ }^{2}}+\sqrt{t_{9}{ }^{2}}+\sqrt{t_{19}{ }^{2}+t_{20}{ }^{2}+t_{21}{ }^{2}+t_{25}{ }^{2}+t_{26}{ }^{2}+t_{27}{ }^{2}}\right)
\end{aligned}
$$

The constraint conditions are as follows:

$$
\begin{aligned}
& \Delta x_{\max } \leq \operatorname{def}(\Delta x) \\
& \Delta y_{\max } \leq \operatorname{def}(\Delta y) \\
& \Delta z_{\max } \leq \operatorname{def}(\Delta z) \\
& l b\left(\Delta s_{i}(u)\right) \leq \Delta s_{i}(u) \leq u b\left(\Delta s_{i}(u)\right) \\
& (i=1,2,3 ; u=x, y, z, A, B) \\
& l b\left(S_{300 P}(u)\right) \leq S_{300 P}(u) \leq u b\left(S_{300 P}(u)\right) \\
& (u=x, y, z, A, B)
\end{aligned}
$$

In Eq. (20) $M_{1}$ represents total cost function; $M_{2}$ represents Euclidean norm function of all the parameters variable. According to the requirement of user's processing precision, the maximum allowable error in $\mathrm{X}$, $\mathrm{Y}, \mathrm{Z}$ direction of the five axis machining center are:

$$
\operatorname{def}(\Delta x)=-0.015, \operatorname{def}(\Delta y)=0.015, \operatorname{def}(\Delta z)=0.01
$$

At the same time, in order to achieve the optimization objective, the optimized error should not be less than standard value, and accuracy parameters of the same parts should not be too much difference. Therefore, the 
standard value is taken as the lower bound of the variable, and the 3 times of the standard value is taken as the upper bound of the variable.

\section{Accuracy optimization allocation based on NSGA-II}

The ISIGHT and MATLAB integration method will be applied to optimize the above multi-objective optimization problem. The above two objective functions are as the target function, and after the variables constraints range of the 37 geometric errors and requirements of machine tool precision are set, NSGA- II can be used to optimize the 37 geometric errors through combining with MATLAB. Optimization results are shown in Table 4.

Table 4. The optimization results of the five-axis machining center 37 geometric errors.

\begin{tabular}{|c|c|c|c|c|c|}
\hline Error terms & Standard values (mm) & Optimal values (mm) & Error terms & Standard values (mm) & $\begin{array}{c}\text { Optimal values } \\
(\mathrm{mm})\end{array}$ \\
\hline$\Delta x_{x}$ & 0.005 & 0.0150 & $\Delta \beta_{x}$ & $0.003125 / 1000$ & $0.009342 / 1000$ \\
\hline$\Delta y_{x}$ & 0.005 & 0.0150 & $\Delta \gamma_{x}$ & $0.003125 / 1000$ & $0.003215 / 1000$ \\
\hline$\Delta z_{x}$ & 0.005 & 0.0150 & $\Delta \alpha_{y}$ & $0.003125 / 1000$ & $0.009323 / 1000$ \\
\hline$\Delta x_{y}$ & 0.005 & 0.0100 & $\Delta \beta_{y}$ & $0.003125 / 1000$ & $0.009331 / 1000$ \\
\hline$\Delta y_{y}$ & 0.005 & 0.0150 & $\Delta \gamma_{y}$ & $0.003125 / 1000$ & $0.003126 / 1000$ \\
\hline$\Delta z_{y}$ & 0.005 & 0.0150 & $\Delta \alpha_{z}$ & $0.003125 / 1000$ & $0.003126 / 1000$ \\
\hline$\Delta x_{z}$ & 0.005 & 0.0150 & $\Delta \beta_{z}$ & $0.003125 / 1000$ & $0.003281 / 1000$ \\
\hline$\Delta y_{z}$ & 0.005 & 0.00866 & $\Delta \gamma_{z}$ & $0.003125 / 1000$ & $0.003138 / 1000$ \\
\hline$\Delta z_{z}$ & 0.005 & 0.00827 & $\Delta \alpha_{A}$ & $0.04 / 1000$ & $0.007509 / 1000$ \\
\hline$\Delta x_{A}$ & 0.0075 & 0.0231 & $\Delta \beta_{A}$ & $0.0075 / 1000$ & $0.04026 / 1000$ \\
\hline$\Delta y_{A}$ & 0.0075 & 0.0206 & $\Delta \gamma_{A}$ & $0.0075 / 1000$ & $0.008015 / 1000$ \\
\hline$\Delta z_{A}$ & 0.0075 & 0.00801 & $\Delta \alpha_{B}$ & $0.0075 / 1000$ & $0.007531 / 1000$ \\
\hline$\Delta x_{B}$ & 0.0075 & 0.0225 & $\Delta \beta_{B}$ & $0.04 / 1000$ & $0.04001 / 1000$ \\
\hline$\Delta y_{B}$ & 0.0075 & 0.0218 & $\Delta \gamma_{B}$ & $0.0075 / 1000$ & $0.009955 / 1000$ \\
\hline$\Delta z_{B}$ & 0.0075 & 0.00790 & $\Delta \gamma_{x B}$ & $0.0125 / 300$ & $0.01251 / 300$ \\
\hline$\Delta \gamma_{x y}$ & $0.005 / 500$ & $0.0108 / 500$ & $\Delta \alpha_{z B}$ & $0.0125 / 300$ & $0.01503 / 300$ \\
\hline$\Delta \beta_{x z}$ & $0.005 / 500$ & $0.0050 / 500$ & $\Delta \gamma_{y A}$ & $0.0125 / 300$ & $0.01263 / 1000$ \\
\hline$\Delta \alpha_{y z}$ & $0.005 / 500$ & $0.0050 / 500$ & $\Delta \beta_{z A}$ & $0.0125 / 300$ & $0.01486 / 1000$ \\
\hline$\Delta \alpha_{x}$ & $0.003125 / 1000$ & $0.009374 / 1000$ & & & \\
\hline
\end{tabular}

\section{Conclusions}

Table 4 shows that all the variables optimized are less than the standard value. At the same time, the value of $e_{x}$, $e_{y}, e_{z}$ are at the maximum allowable error range. It shows that the geometric errors are appropriate amplification in the premise of ensuring the processing precision of machine tool, so that it can avoid improving the precision grade of the key components blindly in the production process in order to improve the precision of the machine tool. It is found that through the optimization method in this paper, it was able to appropriately enlarge the geometric errors, which can reduce the manufacturing cost of the machine tool, in the premise of ensuring the machining accuracy of the machine tool.

\section{Acknowledgement}

The authors are most grateful to National Natural Science Foundation of China (51575010), Beijing Nova Program (Z1511000003150138), The Leading Talent Project of Guangdong Province, Open Research Fund of Key Laboratory of High Performance Complex Manufacturing, Central South University (Kfkt2014-09), Shantou Light Industry Equipment Research Institute of science and technology Correspondent Station 
(2013B090900008), which support the research presented in this paper.

\section{References}

1. M.Anjanapva, D.K.Anand, J.A.Kirk. Error correction methodologies and control strategies for numerical control machines. Control Method for Manufacturing Process. 7:41-49 (1988).

2. P. D. Lin, K. F. Ehmann. Direct volumetric error evaluation for multi-axis machines. International Journal of Machine Tools \& Manufacture. 33, 5: 675-693 (1993).

3. V.Kiridena, P.M.Ferreira. Mapping the effects of positioning errors on the volumetric accuracy of fiveaxis CNC machine tools. International Jounal of Machine Tools \& Manufacture, 33, 3: 417-437 (1993)

4. John C., Ziegert, Prashant Kalle. Error compensation in machine tools: a neural network approach. Journal of Intelligent Manufacturing, 5: 143-151 (1994).

5. Mahbubur Rahman, Jouko Heikkala, Kauko Lappalainen. Modeling measurement and error compensation of multi-axis machine tools. Part 1: theory. International Journal of Machine Tools \& Manufacture, 40: 1535-1546 (2000).

6. Moon S K, Moon Y M, Kota S, et al. Screw theory based metrology for design and error compensation of machine tools. Proceedings of DETC, 1: 697-707 (2001)

7. Yizhong Ma, Shaohua Cheng, Yanjun Li. Improvement of multivariate quality loss function and its empirical analysis. Systems Engineering, 20, 4: 54-58 (2002).

8. Tingting Ai, Jing Tian, Hongchi Gao. A research on the technology of assembly quality optimization based on multiple quality loss and genetic algorithm. China Mechanical Engineering, 10: 1161-1164 (2012).

9. Saisai Duan, Shuhai Fan, Tinghua Huang, Qinghong Xie, Nanyun Jiang. A research on incremental model based on multivariate quality loss function. Machinery Design and Manufacture, 7: 253-256 (2013).

10. Chang, Y.-C., Hung, W.-L. Linex loss functions with applications to determining the optimum process parameters. Qual. Quant, 41: 291-301 (2007).

11. Jen-Ming Chen, Jia-Chi Tsou. An optimal design for process quality improvement: modeling and application. Production Planning \& Control, 14, 7: 603-612 (2003).

12. Ram Ganeshan, Shailesh Kulkarni, Tonya Boone. Production economics and process quality: A Taguchi perspective. Production Economics, 71: 343-350 (2001).

13. Noel Artiles-León. A pragmatic approach to multiple-response problems using loss functions. Quality Engineering, 9, 2: 213-220 (1996).

14. Ramesh Kumar, L., Padmanaban, K.P., Balamurugan, C. Least cost-tolerance allocation based on Lagrange multiplier. Concurrent Engineering Research and Applications, 24, 2: 164-177 (2016).

15. Balamurugan, C., Saravanan, A., Dinesh Babu, P., Jagan, S., Ranga Narasimman, S. Concurrent optimal allocation of geometric and process tolerances based on the present worth of quality loss using evolutionary optimisation techniques. Research in Engineering Design, 1-18 (2016).

16. Pradeep Kumar Gupta1, Kunal Sharma, and Vibhu Tripathi. Economical Analysis and Up Gradation of Existing Machine Tools through Retrofitting. International Journal of Mechanical Engineering and Robotics Research, 2, 4: 52-58(2013).

17. Manikandan, R., Swaminathan, P., Sujitha, R. Unimodular hypergraph based clustering approaches for VLSI circuit partitioning. International Journal of Engineering and Technology, 5, 3: 2755-2758 (2013).

18. Shijin Kumar, P.S., Dharun, V.S. Hybrid brain MRI segmentation algorithm based on $\mathrm{K}$-means clustering and texture pattern matrix. International Journal of Applied Engineering Research, 11, 6: 4343-4348 (2016).

19. Daie, P., Li, S. Matrix-based hierarchical clustering for developing product architecture. Concurrent Engineering Research and Applications, 24, 2: 139152 (2016).

20. Jinyuan Tang,Yanfeng Lu, Chao Zhou. Contact analysis of spiral bevel gear transmission with error. Chinese Journal of Mechanical Engineering, 44, 7: 16-23 (2008).

21. Fang Kang, Jinwei Fan. Optimal allocation method of NC machine tool manufacturing precision. Mechanical Science and Technology, 27, 5: 588-591 (2008).

22. Lloyd S. Nelson. Some notes on variation. Journal of Quality Technology, 31, 4: 459-462 (1991).

23. Wen $\mathrm{Wu}$, Weishe Zhang. Tolerance optimal allocation method based on manufacturing and quality loss cost. Journal of Chang 'an University (Natural Science Edition), 25, 3 (2005). 